\title{
A REVIEW OF THE TAKE-HOME EXPOSURE PATHWAY OF WORKPLACE HAZARDS
}

Siti Marwanis Anua ${ }^{1 *}$, Sean Semple ${ }^{2}$, Siti Farhanah Md Shakri ${ }^{1}$, Sabreena Safuan ${ }^{1}$, Nurzafirah Mazlan $^{3}$, Amiratul Aifa Mohamad Asri ${ }^{1}$

\begin{abstract}
Para-occupational exposure has been reported in the literature with increase in the risk of ill health among spouses, children and family members of workers exposed to materials like asbestos, heavy metals and pesticides. The family members are exposed to workplace agents brought home via the pathway of the take-home exposures routes such as on skin, clothes, shoes and cars. Hence the purpose of this review is to: demonstrate the evidence of take-home exposure pathway of chemicals such as pesticides, lead and asbestos; discuss sources and factors of take-home exposure; and consider methods to reduce the risk of take-home exposures.
\end{abstract}

Keywords: take-home, para-occupational, exposure pathway

1. School of Health Sciences, Health Campus, Universiti Sains Malaysia, 16150 Kubang Kerian, Kelantan, Malaysia.

2. Institute for Social Marketing, Faculty of Health Sciences and Sport, University of Stirling, Stirling, FK9 4LA, Scotland.

3. Department of Diagnostic and Allied Health Sciences, Faculty of Health and Life Sciences, Management and Science University, University Drive, Seksyen 13, 40100 Shah Alam, Selangor, Malaysia.

\author{
*Corresponding Author \\ Dr. Siti Marwanis Anua \\ Lecturer \\ Environmental and Occupational Health, \\ School of Health Sciences, \\ Health Campus, Universiti Sains \\ Malaysia, 16150 Kubang Kerian, \\ Kelantan, Malaysia. \\ Email: smarwanis@usm.my
}

\section{Introduction}

The term 'take-home exposure' is also referred to as para-occupational exposure. Based on the legal aspect take-home is defined as 'house-hold', 'bystander', 'secondary', 'second-hand' which referred to those who was never enter the premises or use the material at issue but were nonetheless exposed ${ }^{1}$. The potential for workplace hazards to be taken home to workers' family members has become of particular importance due to the potential health effects attributed by occupational contaminants brought into the home by the workers.

Evidence from the scientific literature suggests a wide range of occupational substances can be transported from the workplace to the home environment. These include pesticides ${ }^{2-3}$, asbestos ${ }^{4-5}$, lead ${ }^{6-8}$ and beryllium ${ }^{9}$. Rinehart and Yanagisawa ${ }^{10}$ estimated that 14,000 to 15,000 underground workers potentially carried home lead and tin based on reported previous studies on paraoccupational exposure of lead and tin among electric cable splicers. Sterling, Rosenbaum and Weinkam ${ }^{11}$ suggested that studies include details on the occupation of parents as one factor that could have contributed to childhood lung diseases. Evidence of para-occupational exposure has motivated the United States (US) Congress to pass the "Workers' Family Protection Act" in 1992. This act requires the investigation of the risk to family members from hazardous materials brought home by workers ${ }^{11}$.

\section{Population at risk for take-home exposure}

The population at risk from take-home exposures are members of the household where the worker may transfer the contaminants from work to their houses. This includes houses that function as workplaces. Factors such as age, health status, behaviour and education may contribute to the susceptibility in establishing the adverse health effects among family members who are exposed to the take-home contaminants compared to the workers themselves ${ }^{12}$.

Young children have small body size and rapid development that may cause them to be at greater risk from occupational contaminants 'carried home' by their parents from the workplace ${ }^{13}$. Moreover, they are at higher risk for hazard exposure as they generally spend more time on floors, hand-to-mouth activity behaviours and their gastrointestinal efficiency of contaminant absorption exceeds that of adults ${ }^{14-15}$. 
Women may be at particular risk due to the tendency for them to carry out a greater proportion of housework including laundry and cleaning tasks. For example, wives of beryllium-exposed workers shook off their husbands' clothes covered with gray-black beryllium soot before washing and were exposed to inhaled beryllium at home (as cited by Sanderson et al. ${ }^{9}$ ). This behaviour also suggested both workers and their wives were not aware of the risk of take-home beryllium contamination.

\section{Evidence of take-home exposure}

There have not been any comprehensive studies conducted measuring the take-home phenomenon of substances except a study on lead in the US ${ }^{15-16}$ and flour allergens in Scotland ${ }^{17}$. Most studies have lacked any quantitative exposure assessment and have tended to only investigate the health effects of living with a worker from a particular industry ${ }^{4-5}, 18-19$. Some have used qualitative exposure assessment ${ }^{20-21}$ while others have established the pathways of take-home exposure but health outcomes were not investigated ${ }^{7,22}$. Several studies have lacked comparisons between exposed and non-exposed subjects ${ }^{4,8,19}$, and others did not measure objectively the mechanisms of contamination transfer from work to home ${ }^{5,23}$ and some did not present the measurement levels of contaminants among the exposed workers for establishing such substance sourced from the workplace ${ }^{7}$. Nonetheless, although it would also be prudent if the potential pathway of the take-home exposure was investigated objectively, these studies were able to suggest that the take-home pathway of exposure does exist.

\section{Pesticides}

Vida and Moretto $^{24}$ in their critical review concerning pesticides suggested that the existence of a takehome pathway for pesticides contributed to increased indoor home pesticide contamination and potential exposure to children. The take-home exposure pathway of pesticides was significantly associated with the agricultural tasks of parents ${ }^{2,25-26}$. For example, pesticide metabolites in the urine of children whose parents worked in pear orchards were higher than children whose parents worked on berries or cherries ${ }^{27}$ and pesticide levels in house dust from handlers' homes was higher than levels from tree fruit thinners' homes ${ }^{25}$. Pesticide handlers have the greatest risk for direct exposure to pesticides at times where pesticides are most highly toxic. It has been shown children of agricultural workers have higher exposures than children of non-agricultural workers $^{28}$, there was correlation between pesticide metabolite levels of adults and children in the same household ${ }^{29}$ and between pesticides home and vehicle dust levels with both workers' and children's urine metabolites $^{2}$. A study of Thai farmers suggested exposure to pesticides among their families during the spraying season occurs mainly through contamination of home environment and direct transfer from the farmer to family members. However no correlation was found between farmers' urinary metabolite levels and those of their spouses or children ${ }^{30}$ although this might be due to the small sample size.

\section{Asbestos}

Studies on health effects of family members of asbestos workers such as asbestosis, mesothelioma, pleural plaques and cancer have been reported ${ }^{4-5}, 19,31-35$. Twenty percent of mesothelioma cases were attributed to 'para-occupational' exposure ${ }^{32}$ and numerous forms of asbestos fibres were reported to be found in the lung of family members of exposed workers ${ }^{35}$. A large cohort study in Italy among wives of asbestos workers has associated household exposures (estimated as period of time the husband had worked with asbestos) with increased risk for mesothelioma, but no association with lung cancer ${ }^{4}$. Sider et $a{ }^{19}{ }^{19}$ also studied the abnormality of chest radiographic images from wives of asbestos workers and related year of first exposure as a significant factor of 'para-occupational' exposure. The limitations of both these studies were that they failed to present the levels of asbestos and the comparison was made within the population ${ }^{4},{ }^{19}$. Kilburn and colleagues $^{5}$ studied radiologic prevalence of asbestosis among wives, sons and daughters (without occupational exposures) of asbestos workers and found the presence of radiologic abnormalities was higher compared with two groups of non-exposed controls. They suggested that asbestos fibres were carried home although the pathway mechanism was not described.

\section{Lead}

The meta-analysis of Roscoe et al. ${ }^{36}$ suggested that children of lead-exposed workers have a high risk of developing elevated blood lead levels. They further estimated that out of 1,378,060 men and women in the US who were exposed to inorganic lead at work, about 723,500 worked in industries with potential for take-home lead exposure, with two-thirds of these being at significant risk of take-home exposure ${ }^{36}$.

Whelan et al. (1997) found that children of lead-exposed construction workers were six times more likely to have an elevated blood lead level with higher levels of lead dust in their homes compared to non-exposed children ${ }^{15}$. 
The correlation between blood lead level and environmental lead dust among lead-exposed construction workers' children indicated the importance of the take-home phenomenon. A companion article filled the knowledge gaps by measuring the lead dust levels on hands, cars and homes and demonstrated a plausible occupational pathway of lead contamination from workers' hands, clothing and shoes, into their cars, and then into their homes with high correlation between their children' blood lead levels and dust lead levels at home. However it was limited in representativeness because only workers with high blood lead levels were recruited ${ }^{16}$.

A study in Thailand found that the lead levels in wipe samples were significantly higher in homes of boatcaulkers compared with non-exposed controls' homes with matched distance to the boat-yard ${ }^{7}$. Virji and colleagues $^{8}$ showed lead contamination on worker's skin on departure from work following clean-up, respirators, the decontamination unit and their private cars indicating significant potential for take-home lead exposure.

\section{Sources of take-home contaminations and its pathway}

Previous studies have shown similar pattern of the pathway on how the contaminants were transmitted from workplace to home environment. Jones and Burstyn ${ }^{37}$ in their review postulated the conceptual model of takehome exposures based on the conceptual models of occupational dermal ${ }^{38}$ and inhalation exposure ${ }^{39}$. This model includes three broad pathways: external contamination; internal dose; and behaviour change. Contaminants from workplace could be in the form of chemical, physical or biological which then would contaminate workers externally or internally via dermal, inhalation or ingestion exposure. External contamination occurs when a worker is in direct contact with contaminants such as shoes, clothes and tools. External contamination would lead to environmental contamination once a worker leaves his workplace with contaminated items. Zirschy ${ }^{40}$ has previously provided a comprehensive mathematical description of the external contamination. Finally, workers could get internally exposed when hazardous substances enter their bodies which would lead to health effects. Workers inadvertently carry home work contaminants on their $\operatorname{skin}^{17}$, clothes ${ }^{9,}{ }^{41}$, shoes ${ }^{17,28}$, hair ${ }^{22}$, work tools and vehicles ${ }^{16}$; leading to exposure of their family members with contamination from workplaces. Figure 1 shows the potential routes of take-home exposure pathway.
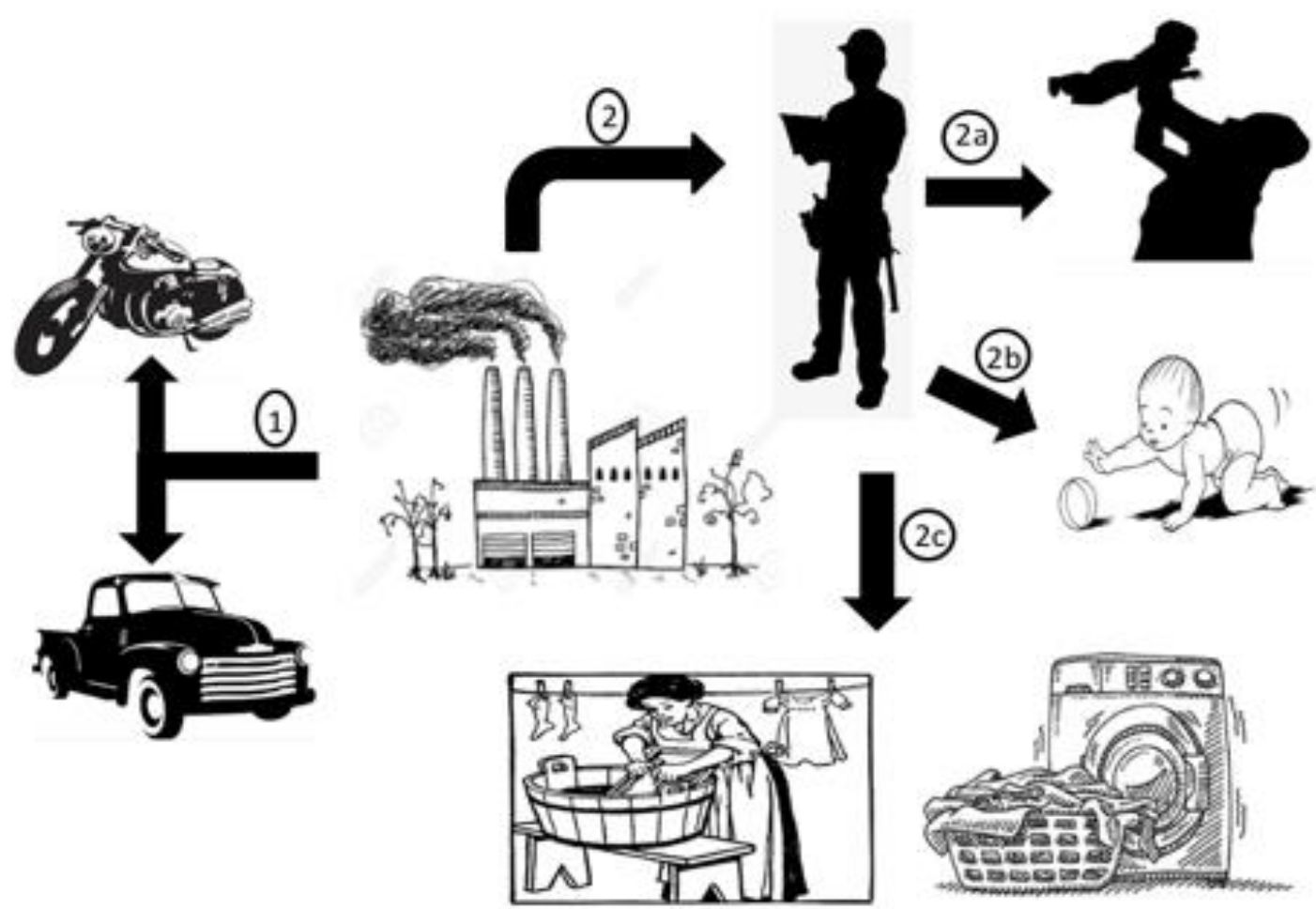

Figure 1: Possible pathway of take-home exposure. (1): Vehicles of the workers exposed to the contaminations from the workplaces brought into cars via clothes and shoes. (2): The workers who are exposed at the workplace act as the vector or primary source of the take-home contaminants via skin, clothes and shoes, as well as bring home work tools. (2a): The workers played with their children once arrived home from workplace, without changing the work clothes or washing. (2b): The dust or contamination then deposits on the floor making crawling infants are at higher risk since they spend most of the time playing and crawling on the floor. They also exhibit frequent hand-to-mouth activities increasing 
the potential of exposure. (2c): Other household members may wash the work clothes of the worker and soare at high risk of take-home exposure from the contaminated clothes and if the contaminated work clothes are laundered together with clothes of family members then there may be cross-contamination.

Source of pictures: Google.com

\section{Workers' skin}

Workers' skin is likely to play an important role in the take-home contamination route. Many studies report contamination on workers' hands, forearm, forehead and feet. Skin contamination often occurs among those who are non-compliant with respect to hygiene practices such as hand washing and showering before leaving the workplace or those who do not immediately shower on arrival at home. For example, workers had lower levels of end of shift skin lead levels when practiced washing hands and showering at the end of the shift and work at sites with good decontamination and hand wash facilities ${ }^{8}$. It has also been demonstrated that children of farmers who washed at home have 22-fold (95\% CI 2 to 337; $\mathrm{p} \mathrm{0.04)} \mathrm{higher} \mathrm{pesticide} \mathrm{metabolite} \mathrm{levels} \mathrm{than} \mathrm{children} \mathrm{of} \mathrm{farmers}$ who washed at work before going home ${ }^{30}$.

Contaminations from workers' skin may have been transferred to the vehicles ${ }^{9}$ and house floor $^{7,13}$. Sanderson $e t$ $a l .{ }^{9}$ found significant correlation of beryllium concentrations between end of shift hands wipe samples and car steering wheel and driver's armrest. In contrast to Virji and colleagues ${ }^{8}$, no significant correlation was found between hand wipes and the car steering wheel and only moderate correlations with car seat wipe lead samples. Elevated hand and foot lead loading levels were also found in the family members of lead-exposed workers when compared to controls, with lower correlation between foot lead loadings and the house floor lead loadings and dust lead content. In contrast, hand and foot lead loadings of controls were moderately correlated with floor lead loadings ${ }^{7}$. This might be due to more time spent at home among family members of controls compared to exposed workers.

\section{Contaminated hair}

Although evidence to support the hypothesis that workplace contamination captured via hair is carried home is scarce, measurements of allergens in workers' homes potentially being carried from work via this route has been reported $^{22}$. Although this study did not measure the allergen contamination of hair directly, Krop and colleagues ${ }^{22}$ were able to demonstrate human hair as one of the main pathway routes with high amount of allergens found on laboratory animal workers' hair-covering caps which correlated significantly with their personal airborne-dust measurements.

Transfer of allergens in environmental settings has been reported by measurement of cat allergen utilising hair washing $^{42}$ and hair vacuuming ${ }^{43}$ and vacuuming of hair dust sample collecting dust mites ${ }^{44}$. These show that hair can be a source of animal allergen transportation to the allergen-free environment.

\section{Contaminated clothes and shoes}

There is a lack of studies that present additional direct measurements of contamination on clothes. Previous studies as reviewed have indicated indirect evidence that substances can be carried home via contaminated clothing and shoes. Alternatively, the information regarding handling of work or street clothes worn at work and the laundering of contaminated clothes at home were gathered by questionnaire. It is suggested that clothing is the potential source of contamination in the homes of exposed workers based on the findings that there was significant substance contamination levels in rooms where contaminated clothing from work were changed compared to rooms where similar activity takes place in non-exposed workers homes, although no measurements of clothing were taken ${ }^{16,23}$.

More evidence to suggest that clothing is a potential source of contamination is from elevated contamination levels in children whose parents wore contaminated clothing at home. For example, one case series reported elevated lead levels in children whose fathers were occupationally exposed to lead and who reportedly brought home their work clothes ${ }^{45-46}$. In addition to that, Vissers, Doekes and Heederik ${ }^{23}$ found that there is transportation of contaminants from the bakery to the homes of bakers via their shoes especially among those who wore shoes in the house. Lu et al. ${ }^{28}$ found that wipe samples taken from parents' work boots showed the highest frequency of take-home pesticides. However, they were unable to find an association between hygiene practices such as using doormats, removal of work shoes and work clothes before entering the home, separating work clothes for laundering and frequent home vacuuming with pesticide levels at home and pesticide metabolites in children. 


\section{Taking items home from work}

Besides taking home contaminated items from work such as clothes and shoes as reported in the studies discussed earlier, workers may take their work tools and equipment with them, or transport them in vehicles ${ }^{12}$ or take home items from work for their own use ${ }^{29,47}$. For example, an asbestos worker took home cotton cloth sacks that had been used to transport moulded insulation, to make diapers (nappies) for his children. The oldest child died of mesothelioma at age 32 years while the mother who had laundered the diapers and her husband's work clothes died of mesothelioma at age $49^{47}$. It is also possible for farm workers to take pesticides from the workplace for residential use ${ }^{29}$. In a similar way is also possible that bakery workers who work on their own in small craft bakeries may use their own private cars for delivery or use their delivery vehicle for private use and transport of family members.

\section{Contaminated vehicles}

Vehicles can serve as both "reservoir" and "vector" (terms used to describe the potential of vehicles to function as a location where the hazardous material is stored and exposure takes place, or can be the means by which the material is transported from one place to another) for substances to be taken home, as well as a microenvironment for agents' exposure because this small compartment of environment is accessible by all family members. Previous studies have found high contamination levels of substance ${ }^{16}$ or highest vehicle levels on the drivers' floor ${ }^{9}$ among exposed workers compared to non-exposed indicating that workers carrying workplace contaminants on hands, shoes and clothing. Significant correlation was found between home and vehicle dust concentration ${ }^{2}, 29$ and association between vehicle concentration and the workers' and children' urine metabolite levels ${ }^{2}$. Bernier et al. ${ }^{48}$ reported six cases of take-home lead contamination among children of lead-exposed workers with positive child seat contamination. However, Sanderson et al. ${ }^{9}$ found no detectable beryllium on three child seats in the cars although they reported the highest beryllium vehicle levels was on the drivers' floor.

\section{Workplace visit by family members}

Workplace visits by family members can also contribute to the take-home contamination of substances. Although this deviates from the concept of parents taking home contamination it is relevant for para-occupational exposure. For example, in the case that children can develop baker's asthma upon exposure to flour, there is a report of a two-year old exposed when visiting his grandfather's bakery ${ }^{49}$. While visiting parents' workplace, three of five children who showed specific IgE antibodies to laboratory animal allergens complained of rhinitis and cough ${ }^{18}$.

\section{Occupational choices and hobbies}

The familial aggregation of occupational choice of the children' by parental occupation is another important issue to consider. Children who follow their parents' occupation might actually be sensitised before they start work (with respect to respiratory sensitisers). For example, the possibility that parents who work with animals may be more likely to have pets at home might also increase the risk of exposure 'outside of work' to respiratory sensitisers among their family members. Another factor to consider is hobby-related exposure. Bakers and car painters with high interest in their job may have a high tendency to do similar work at home; by supplying homemade baking to friends and relatives or having their own garage to work on after work hours. There is also the possibility that such hobbies would involve their family members or children. This may also increase the risk of exposure to similar hazards that the worker encounters in the workplace.

\section{Prevention and control of take-home exposure}

Whilst take-home exposure of workplace hazardous material continues to occur, an improved control strategy and hygiene practices that work best in preventing the transport of contaminants from workplace to homes should be identified. Some examples are as tabulated in Table 1.

Educational intervention programs to prevent home contamination should be developed for employers, workers, children, teachers, parents, physicians and other health professionals. For example, hygienists could go to workplaces and measure take-home contamination on staff leaving worksites for the purpose of showing whether the current decontamination procedures are effective in preventing the take-home pathway of contaminants. Employers should make available written policy and control measures, and enforce these policies. Physicians should also be aware of para-occupational exposure and include questions on parental or spouse occupation when taking a medical history. 
Table 1. Suggestion of prevention and control in reducing the take-home exposure of workplace hazards.

\begin{tabular}{|l|l|}
\hline Bil. & Description of controls \\
\hline 1. & reducing exposures in the workplace \\
\hline 2. & $\begin{array}{l}\text { floor and work surfaces should be 'wet' cleaned } \\
\text { regularly and dry dusting and brushing should be } \\
\text { avoided }\end{array}$ \\
\hline 3. & $\begin{array}{l}\text { decontamination of agents from skin using suitable and } \\
\text { efficient washing methods }\end{array}$ \\
\hline 4. & showering before leaving the workplace \\
\hline 5. & $\begin{array}{l}\text { showering immediately on returning home if it is not } \\
\text { possible to do it at workplace } \\
\text { changing work clothes (and work shoes) before going } \\
\text { home }\end{array}$ \\
\hline 6. & $\begin{array}{l}\text { leaving the contaminated clothes (and shoes) at work to } \\
\text { be laundered by the employers }\end{array}$ \\
\hline 8. & $\begin{array}{l}\text { contaminated clothes (or work shoes) or disposable } \\
\text { coveralls (or overshoes) should be cleaned or disposed } \\
\text { accordingly }\end{array}$ \\
\hline 9. & $\begin{array}{l}\text { storing street clothes (or street shoes) in separate areas } \\
\text { at the workplace to prevent their contamination }\end{array}$ \\
\hline 10. & $\begin{array}{l}\text { laundering separately from family laundry if it is } \\
\text { necessary to launder the contaminated clothes at home }\end{array}$ \\
\hline 11. & prohibiting taking contaminated items home \\
\hline 12. & separating work areas from living areas \\
\hline 13. & separating work vehicles from personal cars \\
\hline 14. & $\begin{array}{l}\text { ensuring the vehicles used for travel to work are cleaned } \\
\text { regularly }\end{array}$ \\
\hline & \\
\hline
\end{tabular}

\section{Conclusion}

This review has examined evidence of take-home contamination and provided an insight into the potential pathway of take-home exposure at workplaces. It is possible that this pathway of exposure may lead to an increase in the risk of health effects among family members of exposed workers. This review indicates that the majority of studies lack objective measurements of contamination in relation to sources of dermal exposure and how this contributes to the take-home pathway (e.g., on skin, clothing, hair, footwear, cars, and others). However some previous research has described methods of quantitatively investigating the take-home pathway of respiratory sensitisers in the United Kingdom (UK) ${ }^{17}$ and there is a need for standard protocols for similar investigations for pesticides and metals.

There is a lack of information on factors attributing to the transportation of materials from work to home; with very few studies attempting to look at potential variables contributing to the take-home pathway. Despite the potential for increased risk of certain health effects from para-occupational exposures, the majority of studies provide limited data on assessment of levels of take-home of other contaminants such as organic dust. Risks of take-home exposures and some of the factors should be scrutinised and studied further. Further work is also required to determine the effectiveness of hygiene practices at work/home in controlling the take-home exposure pathway.

\section{Acknowledgment}

The authors gratefully acknowledge the financial support from the Research University (RUI) grant (PPSK/1001/812181) and the Short Term grant (304/PPSK/61313094), Universiti Sains Malaysia.

\section{References}

1. Strang CE, Ross KE. 7th annual update of take-home asbestos duty decisions: significant 2016 rulings highlight litigation landscape. Harris Martin's COLUMNS- Asbestos, 2017; Washington Harris Martin Publishing LLC. 
2. Coronado GD, Vigoren EM, Thompson B, Griffith WC, Faustman EM. Organophosphate pesticide exposure and work in pome fruit: Evidence for the take-home pesticide pathway, Environmental health perspectives, 2006;114 (7), 999-1006.

3. Thompson B, Coronado GD, Grossman JE, Puschel K, Solomon CC, et al. Pesticide take-home pathway among children of agricultural workers: Study design, methods, and baseline findings, Journal of Occupational and Environmental Medicine, 2003; 45(1), 42-53

4. Ferrante D, Bertolotti M, Todesco A, Mirabelli D, Terracini B, Magnani C. Cancer mortality and incidence of mesothelioma in a cohort of wives of asbestos workers in Casale Monferrato, Italy, Environmental health perspectives, 2007; 115(10), 1401-1405.

5. Kilburn KH, Lilis R, Anderson HA. Asbestos disease in family contacts of shipyard workers", American Journal of Public Health, 1985; 75(6), 615-617.

6. Newman N, Jones C, Page E, Ceballos D, Oza A. investigation of childhood lead poisoning from parental take-home exposure from an electronic scrap recycling facility - Ohio 2012. In: PAGE, E. (ed.) Morbidity and Mortality Weekly Report. Ohio. 2015.

7. Untimanon O, Geater A, Chongsuvivatwong V, Saetia W, Utapan S. Skin lead contamination of family members of boat-caulkers in Southern Thailand, Industrial health, 2011; 49(1), 37-46.

8. Virji MA, Woskie SR, Pepper LD. Skin and surface lead contamination, hygiene programs, and work practices of bridge surface preparation and painting contractors. Journal of occupational and environmental hygiene, 2009; 6(2), 131-142

9. Sanderson WT, Henneberger PK, Martyny J, Ellis K, Mroz MM, Newman LS. Beryllium contamination inside vehicles of machine shop workers. Applied Occupational and Environmental Hygiene, 1999; 14(4), 223-230

10. Rinehart RD, Yanagisawa Y. Paraoccupational exposures to lead and tin carried by electric-cable splicers. American Industrial Hygiene Association Journal, 1993; 54(10), 593-599.

11. Sterling TD, Rosenbaum WL, Weinkam JJ. Re: "concentration of indoor particulate matter as a determinant of respiratory health in children", American Journal of Epidemiology. 1995; 141(6), 581-582.

12. NIOSH. Protecting workers' families; a research agenda report of the workers' family protection task force, Department of Health and Human Services, Centers for Disease Control and Prevention. 2002.

13. Quandt SA, Arcury TA, Rao P, Snively BM, Camman DE, et al. Agricultural and residential pesticides in wipe samples from farmworker family residences in North Carolina and Virginia, Environmental health perspectives, 2004; 112(3), 382-387.

14. Coronado GD, Griffith WC, Vigoren EM, Faustman EM, Thompson B. Where's the dust? Characterizing locations of azinphos-methyl residues in house and vehicle dust among farmworkers with young children, Journal of Occupational and Environmental Hygiene, 2010; 7(12), 663-671.

15. Whelan EA, Piacitelli GM, Gerwel B, Schnorr TM, Mueller CA, et al. Elevated blood lead levels in children of construction workers, American Journal of Public Health, 1997; 87(8), 1352-1355.

16. Piacitelli GM, Whelan EA, Sieber WK, Gerwel B. Elevated lead contamination in homes of construction workers, American Industrial Hygiene Association Journal, 1997; 58(6), 447-454.

17. Tagiyeva N, Anua SM, Semple S, Dick F, Devereux G. The 'take home' burden of workplace sensitizers: Flour contamination in bakers' families. Environment International, 2012; 46, 44-49.

18. Krakowiak A, Szulc B, Górski P. Allergy to laboratory animals in children of parents occupationally exposed to mice, rats and hamsters, European Respiratory Journal, 1999; 14(2), 352-356.

19. Sider L, Holland, EA, Davis Jr., TM, Cugell DW. Changes on radiographs of wives of workers exposed to asbestos, Radiology, 1987; 164(3), 723-726.

20. Tagiyeva N, Devereux G, Semple S, Sherriff A, Henderson J, Elias P, Ayres JG. Parental occupation is a risk factor for childhood wheeze and asthma, European Respiratory Journal, 2010; 35(5), 987-993.

21. Magnusson LL, Wennborg H, Bonde JP, Olsen J. Wheezing, asthma, hay fever, and atopic eczema in relation to maternal occupations in pregnancy, Occupational and Environmental Medicine, 2006; 63(9), 640646.

22. Krop EJM, Doekes G, Stone MJ, Aalberse RC, Van Der Zee JS. Spreading of occupational allergens: Laboratory animal allergens on hair-covering caps and in mattress dust of laboratory animal workers, Occupational and Environmental Medicine, 2007; 64(4), 267-272.

23. Vissers M, Doekes G, Heederik D. Exposure to wheat allergen and fungal $\alpha$-amylase in the homes of bakers, Clinical and Experimental Allergy, 2001; 31(10), 1577-1582.

24. Vida P, Moretto A. Pesticide exposure pathways among children of agricultural workers, Journal of Public Health, 2007; 15(4), 289-299.

25. Fenske RA, Lu C, Negrete M, Galvin K. Breaking take-home pesticide exposure pathway for agricultural families: workplace predictors of residential contamination. American Journal of Industrial Medicine, 2013; 56 (9), 1063-1071. 
26. Coronado GD, Thompson B, Strong L, Griffith WC, Islas I. Agricultural task and exposure to organophosphate pesticides among farmworkers, Environmental health perspectives, 2004; 112(2), 142-147.

27. Lambert WE, Lasarev M, Muniz J, Scherer J, Rothlein J, et al. Variation in organophosphate pesticide metabolites in urine of children living in agricultural communities, Environmental Health Perspectives, 2005; 113(4), 504-508.

28. Lu C, Fenske RA, Simcox NJ, Kalman D. Pesticide exposure of children in an agricultural community: Evidence of household proximity to farmland and take home exposure pathways, Environmental Research, 2000; 84(3), 290-302.

29. Curl CL, Fenske RA, Kissel JC, Shirai JH, Moate TF, et al. Evaluation of take-home organophosphorus pesticide exposure among agricultural workers and their children, Environmental Health Perspectives, 2002; 110(12), A787-A792.

30. Hanchenlaksh C, Povey A, O'Brien S, de Vocht F. Urinary DAP metabolite levels in Thai farmers and their families and exposure to pesticides from agricultural pesticide spraying, Occupational and Environmental Medicine, 2011; 68, 625-627.

31. Noonan CW. Environmental asbestos exposure and risk of mesothelioma. Annals of Translational Medicine, $2017 ; 5,234$.

32. Tompa E, Kalcevich C, Mcleod C, Lebeau M, Song C, Mcleod K, Kim J, Demers PA. The economic burden of lung cancer and mesothelioma due to occupational and para-occupational asbestos exposure. Occupational Environmental Medicine, 2017; 74, 816-822.

33. Mensi C, Matteis SD, Dallari B, Riboldi L, Bertazzi PA, Consonni D. Incidence of mesothelioma in Lombardy, Italy: exposure to asbestos, time patterns and future projections. Occupational Environmental Medicine, 2016; 73, 607-613.

34. Stayner LT. Para-occupational exposures to asbestos: lessons learned from Casale Monferrato, Italy. Occupational Environmental Medicine, 2016; 73, 145-146.

35. Sahmel J, Barlow CA, Simmons B, Gaffney SH, Avens HJ, et al. Evaluation of take-home exposure and risk associated with the handling of clothing contaminated with chrysotile asbestos. Risk Analysis, 2014; 34, $1448-1468$.

36. Roscoe RJ, Gittleman JL, Deddens JA, Petersen MR, Halperin WE. Blood lead levels among children of lead-exposed workers: A meta- analysis, American Journal of Industrial Medicine, 1999; 36(4), 475-481.

37. Jones RM, Burstyn I. A conceptual model for take-home workplace exposures, Journal of Occupational and Environmental Hygiene, 2018; 15(1): D8-D11

38. Schneider T, Vermeulen R, Brower D, Cherrie J, Kromhout H, Fogh C. Conceptual assessment of dermal exposure. Occup. Environ. Med. 19999; 56:765-773

39. Tielemans E, Schneider T, Goede H, Tischer M, Warren N, et al. Conceptual model for assessment of inhalation exposure: Defining modifying factors, Annals of Occupational Hygiene, 2008; 52(7), 577-586.

40. Zirschky J. Take-home toxin pathway. J. Env. Eng. 1996; 122:430-436.

41. De Lucca SD, O'Meara TJ, Tovey ER. Exposure to mite and cat allergens on a range of clothing items at home and the transfer of cat allergen in the workplace, Journal of Allergy and Clinical Immunology, 2000; 106(5): 874-879.

42. Karlsson A, Renström A. Human hair is a potential source of cat allergen contamination of ambient air, Allergy: European Journal of Allergy and Clinical Immunology, 2005; 60(7): 961-964.

43. Liccardi G, Barber D, Russo M, D'Amato M, D'Amato G. Human hair: An unexpected source of cat allergen exposure, International Archives of Allergy and Immunology, 2005; 137(2), 141-144.

44. Siebers RW, Rains N, Fitzharris P, Crane J. House dust mite allergen (Der p 1) in human hair, Journal of Allergy and Clinical Immunology, 1998; 101(3), 421-422.

45. Gerson M, Van Den Eeden SK, Gahagan P. Take-home lead poisoning in a child from his father's occupational exposure, American Journal of Industrial Medicine, 1996; 29(5), pp. 507-508.

46. Hipkins KL, Materna BL, Payne SF, Kirsch LC. Family lead poisoning associated with occupational exposure, Clinical Pediatrics, 2004; 43(9), 845-849.

47. Li FP, Dreyfus MG, Antman KH. Asbestos-contaminated nappies and familial mesothelioma, Lancet, 1989; 1(8643), 909-910.

48. Bernier T, Lee S, May A, Frohmberg E, Smith A, et al. 2009. Childhood lead poisoning associated with lead dust contamination of family vehicles and child safety seats - Maine, Morbidity and Mortality Weekly Report, 2008; 58(32), 890-893.

49. Moreno-Escobosa MC, Lebrero EA, Ausín A, Elices A, Ibañez MD, Laso MT. Baker's asthma in a child, Allergologia et Immunopathologia, 2001; 29(4), 141-143. 